\title{
A cross-sectional study of female sexual dysfunction among Turkish pregnant and nonpregnant women: correlation with hormone profile
}

\author{
Bahar Saruibrahim Astepe ${ }^{1} \odot$, Ișıll Köleli² ${ }^{2}$ \\ ${ }^{1}$ Department of Obstetrics and Gynecology, University of Health Sciences, Derince Training and Research Hospital, Kocaeli, Turkey, \\ Turkey \\ ${ }^{2}$ Department of Obstetrics and Gynecology, İn̈nü University School of Medicine, Malatya, Turkey
}

DOI: 10.18621 /eurj.432490

\begin{abstract}
Objectives: To determine the prevalence of female sexual dysfunction (FSD) and its correlation with the androgenic hormones among pregnant and nonpregnant Turkish women.

Methods: This was a cross-sectional study of 251 women, including 137 healthy pregnant and 114 healthy nonpregnant Turkish women. Assessment of female sexual function index (FSFI), sociodemographic characteristics, serum androgen levels, including the total testosterone, dehydroepiandrosterone sulfate (DHEAS), 1-4 delta androstenedione.

Results: There was a $65.7 \%$ incidence of FSD in all of the participants, with an incidence of $58.8 \%$ in the pregnant and $41.2 \%$ in the nonpregnant women. There was no significant difference in the FSFI total scores between the pregnant and nonpregnant women $(p>0.05)$. Moreover, the androgen levels were not different between the women with sexual dysfunction and those without. The Spearman correlation test results were significant between the total testosterone level and the FSFI arousal domain $(\mathrm{r}=0.167, p<0.05)$, FSFI lubrication domain $(\mathrm{r}=0.264, p<0.01)$, and FSFI total score $(\mathrm{r}=0.212, p<0.01)$, as well as between the androstenedione level and FSFI lubrication domain $(\mathrm{r}=0.211, p<0.01)$, FSFI orgasm domain $(\mathrm{r}=0.156, p<$ $0.05)$, and FSFI total score $(\mathrm{r}=0.174, p<0.05)$. In the logistic regression analysis for sexual dysfunction, an increase in the DHEAS level increased the sexual dysfunction by 0.996 -fold. Women with one pregnancy had 3.312-fold greater sexual dysfunction than those with no pregnancies. Moreover, the women with more than eight years of education had 0.358 times more sexual dysfunction than those with eight years of education and less.

Conclusion: The FSFI total scores were not significantly different between the pregnant and nonpregnant women. However, there were significant correlations between the total testosterone and androstenedione levels and the FSFI total scores. Any increases in the DHEAS level and educational level in women decrease the chance of developing sexual dysfunction.
\end{abstract}

Keywords: Female sexual function index, androgens, pregnancy

Received: Received: June 9, 2018; Accepted: October 31, 2018; Published Online: November 1, 2018

Address for correspondence: Bahar Saribrahim Astepe, MD., University of Health Sciences, Derince Training and Research Hospital, Department of Obstetrics and Gynecology, Kocaeli, Turkey

E-mail: baharsariibrahim@hotmail.com 
$\mathrm{T}$ he female sexual response cycle is divided into four phases, including desire, arousal (excitement), orgasm, and resolution [1]. With regard to these phases, female sexual dysfunction takes different forms, including the absence of sexual desire, impaired arousal, an inability to achieve orgasm, and pain during sexual activity [1]. It is a multifactorial and underestimated problem with an overall prevalence of $20-50 \%$ [2]. One international survey, the Global Study of Sexual Attitudes and Behaviors (GSSAB), evaluated the sexual problems of 13,882 women from 29 different countries, aged 40 to 80 years old, who responded to a questionnaire in person or on the telephone [3]. The most commonly reported sexual problems were a lack of interest in sex (26$43 \%$ ) and an inability to reach orgasm (18-41\%). For all the different sexual problem types, the highest prevalences were seen in Southeast Asia (Indonesia, Malaysia, the Philippines, Singapore, and Thailand) and the lowest prevalences were seen in Northern Europe (Austria, Belgium, Germany, Sweden, and the United Kingdom) [3]. Cayan et al. [4] evaluated women between the ages of 18 and 65 years old, and they found that the sexual dysfunction prevalence in Turkish women was $46.9 \%$; it was $43.4 \%$ in the study by Aslan et al. [5].

In the literature, a significant decline in sexual activities was shown with increasing gestation [6-8]. The reasons suggested for this decline in the sexual activity during pregnancy was physical discomfort, fear of injury to baby, loss of interest, physical awkwardness, painful coitus and perceived lack of attractiveness [79]. Large and representative studies reported no overall association between birth complication (prenatal mortality, preterm birth, premature rupture of the membranes, low birth weight) and either coital activity or orgasmic frequency unless a sexually transmitted disease is acquired $[10,11]$. Besides parental sexuality during pregnancy has positive effects on the long-term quality of the marital relationship, that is reported as being as better with regard to tenderness and communication at 4 months postpartum and, 3 years later, the relationship is more stable and less affected in the view of both partners [12].

Dehydroepiandrosterone (DHEA) is an androgenic hormone and one of the precursors in the biosynthetic pathway of steroid hormones 13]. It has been suggested that androgens play roles in female sexual function, but the magnitudes of these roles are uncertain [14]. Several randomized controlled trials (RCTs) evaluating the safety profile of DHEA with regard to sexual performance in postmenopausal women found that DHEA had a positive effect on sexual function $[15,16]$, while other RCTs did not $[17,18]$.

Female sexual dysfunction (FSD) is considered to be a public health problem, affecting the quality of life of couples. Pregnancy is a special time that includes physical, psychological, and hormonal changes affecting the sexual lives of women. However, the sexual changes during pregnancy and their relationships to the androgenic hormones require further research. Therefore, the aim of this study was to determine the prevalence of FSD and its correlations with the androgenic hormones among pregnant and nonpregnant Turkish women.

\section{METHODS}

\section{Subjects}

This study was conducted with a total of 251 women, including 137 healthy pregnant and 114 healthy nonpregnant women evaluated at the Derince Training and Research Hospital Obstetrics and Gynecology Clinics between February 2016 and April 2017. The research was carried out with participants aged 18-41 years old who were sexually active (those who were married and reported having sexual intercourse during the previous 4 weeks). The main exclusion criterion was the presence of a chronic systemic/endocrine illness, such as diabetes mellitus, hyperthyroidism, hypothyroidism, and psychiatric problems. Those pregnant women with abnormal ongoing pregnancies, including the risk of miscarriage, preterm labor, and hypertensive disorder, were not enrolled in this study. All of the pregnant patients were given information about sexuality in pregnancy at the pregnancy training outpatient clinic in the same hospital, and their questions were answered by a midwife. They were informed that sexual intercourse is safe during pregnancy, except in conditions of pain, cramping, unexplained vaginal bleeding, premature cervical dilatation, and premature membrane rupture. Those patients who wanted to participate were given a patient information sheet and self-reporting questionnaire. Sixteen of the women 
who agreed to participate were not included in the study since they did not fill out their questionnaires completely.

\section{Design}

This was a cross-sectional observational research study in which the author gathered data over a 15month time period. All of the patients provided blood samples between the hours of 10 am and $3 \mathrm{pm}$ in order to minimize the diurnal variations in the hormone levels. They filled out self-reporting questionnaires, including the Female Sexual Function Index (FSFI) and questions related to their sociodemographic data. The questionnaire related to the sociodemographic data included the participant's educational status, occupational status, income, medical history, and obstetric history, including gravity, parity, abortus, vaginal births, and cesarean sections. The educational status was categorized as $\leq 8$ years (elementary and secondary school) and $>8$ years (high school and university). All of the participants were married.

\section{Ethics}

Ethical approval was provided by the Kocaeli University Ethical Committee, and written informed consent was obtained from all of the participants.

\section{Main Outcome Measures}

The sexual function was measured via the FSFI, which is a validated, self-administered, 19-item questionnaire evaluating sexual function during the previous four weeks with six domains: desire, arousal, lubrication, orgasm, satisfaction, and pain. Rosen et al. [19] constructed the self-reported questionnaire for the assesment of female sexual function. The Turkish validation of the FSFI has been performed previously [20]. Questions 1, 2, 15, and 16 are scored between 1 and 5, while all of the other questions are scored between 0 and 5 . The sum score of each domain obtained from the related questions was multiplied in its coefficient factor (Table 1). The sum score of all of the domains ranged from 2 to 36. Those women having a total score below 25 were considered to have sexual dysfunction 21].

All of the patients gave blood samples for evaluating the hormonal androgen concentrations, including the total testosterone, dehydroepiandrosterone sulfate (DHEAS), and 1-4 delta androstenedione. All of the samples were run simultaneously in the biochemistry laboratory of the same hospital.

The total testosterone (TT) was measured via an Advia Centaur kit (Advia Centaur and Advia Centaur XP Systems, Siemens, USA), which is a competitive immunoassay using direct chemiluminescent technology. The test sensitivity and assay range was $10-1,500 \mathrm{ng} / \mathrm{dL}(0.35-52.1 \mathrm{nmol} / \mathrm{L})$. The DHEAS was also measured using an Advia Centaur kit (Advia Centaur and Advia Centaur XP Systems, Siemens, USA), which is a quantitative competitive immunoassay that uses direct chemiluminescent technology. The test sensitivity and assay range was $3-1,500 \mu \mathrm{g} / \mathrm{dL}(0.08-40.75 \mu \mathrm{mol} / \mathrm{L})$. The $1-4$ delta androstenedione was measured via Agilent Technologies 6460 Triple Quad using LC-MS/MS method. The test sensivitiy was $0.009 \mathrm{ng} / \mathrm{mL}$ and the reportable range was $0.03-500 \mathrm{ng} / \mathrm{mL}$.

\section{Statistical Analysis}

The statistical parameters were computed using the Statistical Package for the Social Sciences version 21.0 (SPSS Inc., Chicago, IL, USA). The continuous variables were expressed as the mean \pm standard deviation and median (minimum-maximum), and the

Table 1. Female sexual function index domain scores

\begin{tabular}{lccccc}
\hline Domain & Item number & Score range & Minimum score & Maximum score & Coefficient \\
\hline Desire & 1,2 & $1-5$ & 2 & 10 & 0.6 \\
Arousal & $3,4,5,6$ & $0-5$ & 0 & 20 & 0.3 \\
Lubrication & $7,8,9,10$ & $0-5$ & 0 & 20 & 0.3 \\
Orgasm & $11,12,13$ & $0-5$ & 0 & 15 & 0.4 \\
Satisfaction & $14,15,16$ & $(0$ or 1$)-5 *$ & 2 & 15 & 0.4 \\
Pain & $17,18,19$ & $0-5$ & 0 & 15 & 0.4 \\
\hline
\end{tabular}

Range for item $14=0-5$; range for items 15 and $16=1-5$ 
categorical variables were expressed as the number and percentage. The Mann-Whitney U test was used in the comparison between the averages of two groups. The Kruskal-Wallis test was used to compare more than two continuous variables. The Spearman correlation test was used for evaluating the relationships between the continuous data, and statistical significance was defined as $p<0.05$. The independent predictors of sexual dysfunction using the possible factors in the multivariate analysis were examined using a logistic regression analysis. Finally, the Hosmer-Lemeshow test was used for the model adaptation. Those cases with less than 5\% type 1 error levels were interpreted as statistically significant.

The GPower 3.1 program Posthoc analysis was used for the power analysis retrospectively. When the effect was 0,50 and the total of $251(114+137)$ cases were analyzed in two independent groups, the power was calculated as 0.97 .

\section{RESULTS}

A total of 251 women (137 pregnant and 114 nonpregnant) with a mean age of $28.57 \pm 6.15$ years old constituted the study group. The obstetric history of the participating women is shown in Table 2. In total, $61.4 \%$ of the women had less than eight years of education, $38.6 \%$ had more than eight years of education, $90.4 \%$ of the women were housewives or unemployed, 9.6\% were working, $78.4 \%$ had low incomes (under 570 US dollars), and $21.6 \%$ had middle incomes (over 570 US dollars) (Table 2).

The mean FSFI total score was $23.08 \pm 5.18$, while the number of women with sexual dysfunction based on an FSFI total score of less than 25 was 165 (65.7\% of all the participants). Of those women exhibiting sexual dysfunction, $58.8 \%$ were pregnant and $41.2 \%$ were not. Of the pregnant women, $70.8 \%$ had sexual dysfunction and 29.2\% did not (Table 2).

Table 2. Demographic ,obstetric characteristics ,FSFI total scores and sexual dysfunction rates of the patients.

\begin{tabular}{|c|c|c|c|c|}
\hline & & Total group & $\begin{array}{c}\text { Pregnancy Present } \\
\mathbf{n}=\mathbf{1 3 7}\end{array}$ & $\begin{array}{c}\text { Pregnancy Absent } \\
n=114\end{array}$ \\
\hline Age (years) & Mean \pm SD & $28.57 \pm 6.15$ & $26.59 \pm 5.1$ & $30.94 \pm 6.4$ \\
\hline BMI & Mean \pm SD & $26.06 \pm 4.99$ & $26.1 \pm 5.0$ & $25.99 \pm 4.99$ \\
\hline \multirow{3}{*}{$\begin{array}{l}\text { Gravidity } \\
\text { n }(\%)\end{array}$} & 0 & $23(9.2)$ & & $23(20.2)$ \\
\hline & 1 & $81(32.3)$ & $53(38.7)$ & $28(24.6)$ \\
\hline & $\geq 2$ & 147 (58.6) & $84(61.3)$ & $63(55.3)$ \\
\hline \multirow{3}{*}{$\begin{array}{l}\text { Number of vaginal birth } \\
\text { n }(\%)\end{array}$} & 0 & $153(61)$ & $86(62.8)$ & $67(58.8)$ \\
\hline & 1 & 45 (17.9) & $24(17.5)$ & $21(18.4)$ \\
\hline & $\geq 2$ & $53(21.1)$ & $27(19.7)$ & $26(22.8)$ \\
\hline \multirow{5}{*}{$\begin{array}{l}\text { Number of caesarean section } \\
\text { n }(\%) \\
\text { Gestational week } \\
\text { n }(\%)\end{array}$} & No & $167(66.5)$ & $103(75.2)$ & $64(56.1)$ \\
\hline & $\geq 1$ & $84(33.5)$ & $34(24.8)$ & $50(43.9)$ \\
\hline & 1.trimester & $42(30.7)$ & $42(30.7)$ & \\
\hline & 2.trimester & $35(25.5)$ & $35(25.5)$ & \\
\hline & 3.trimester & $60(43.8)$ & $60(43.8)$ & \\
\hline \multirow{3}{*}{$\begin{array}{l}\text { Educational attainment } \\
\text { n (\%) } \\
\text { Working condition } \\
\text { n }(\%)\end{array}$} & $\begin{array}{l}\leq 8 \text { years } \\
>8 \text { years }\end{array}$ & $\begin{array}{c}154(61.4) \\
97(38.6)\end{array}$ & $\begin{array}{l}81(59.1) \\
56(40.9)\end{array}$ & $\begin{array}{l}73(64) \\
41(36)\end{array}$ \\
\hline & Not working & $227(90.4)$ & $127(92.7)$ & $100(87.7)$ \\
\hline & Working & $24(9.6)$ & $10(7.3)$ & $14(12.3)$ \\
\hline \multirow{2}{*}{$\begin{array}{l}\text { Income } \\
\text { n }(\%)\end{array}$} & Low & $192(78.4)$ & $111(83.5)$ & $81(72.3)$ \\
\hline & Middle & $53(21.6)$ & $22(16.5)$ & $31(27.7)$ \\
\hline Total FSFI score & Mean \pm SD & $23.08 \pm 5.18$ & $22.95 \pm 5.02$ & $23.25 \pm 5.39$ \\
\hline $\begin{array}{l}\text { FSD present } \\
\text { n }(\%)\end{array}$ & & $165(65.7)$ & $97(70.8)$ & $68(59.6)$ \\
\hline
\end{tabular}

FSFI = Female sexual function index, FSD = Female sexual dysfunction, $\mathrm{SD}=$ standard deviation, BMI = body mass index 
Table 3. Comparisons of FSFI total scores according to the trimesters and Female sexual dysfunction rates seen in trimesters

\begin{tabular}{lcccc}
\hline & $\begin{array}{c}\text { 1. trimester } \\
(\mathbf{n = 4 2 )}\end{array}$ & $\begin{array}{c}\text { 2. trimester } \\
(\mathbf{n = 3 5 )}\end{array}$ & $\begin{array}{c}\text { 3.trimester } \\
(\mathbf{n = 6 0 )}\end{array}$ & $\boldsymbol{p}$ value \\
\hline $\begin{array}{l}\text { FSFI total score } \\
(\text { mean } \pm \text { SD) }\end{array}$ & $24.24 \pm 4.41$ & $22.36 \pm 4.61$ & $22.22 \pm 5.47$ & $0.16^{*}$ \\
FSD $(\%)$ & 64.3 & 82.9 & 68.3 & \\
\hline
\end{tabular}

FSD $=$ Female sexual dysfunction, ${ }^{*}$ Kruskal-Wallis test was done

The female sexual dysfunction rate in the first trimester was $64.3 \%$; it was $82.9 \%$ in the second trimester and $68.3 \%$ in the third trimester. When the FSFI total scores were compared between the trimesters, there was no significant difference between the trimester groups $(p=0.16)$ (Table 3$)$.
When the androgen levels and FSFI total and domain scores of the women with and without sexual dysfunction were compared, there was not any significant differences according to the serum androgen levels between the groups $(p>0.05)$ (Table 4).

Table 4. Distribution of the participants' sexual dysfunction according to the androgen levels, FSFI domain scores, and total FSFI scores

\begin{tabular}{lccccc}
\hline & \multicolumn{2}{c}{$\begin{array}{c}\text { Sexual dysfunction } \\
\text { present }\end{array}$} & \multicolumn{2}{c}{$\begin{array}{c}\text { Sexual dysfunction } \\
\text { absent }\end{array}$} \\
\cline { 2 - 5 } & $\mathrm{n}$ & Mean \pm SD & $\mathbf{n}$ & Mean \pm SD & $\boldsymbol{p}^{\text {value }}$ \\
\hline Total testosterone & 163 & $0.68 \pm 0.47$ & 86 & $0.69 \pm 0.69$ & 0.549 \\
1-4 delta androstenedione & 161 & $2.83 \pm 2.22$ & 86 & $2.55 \pm 1.92$ & 0.366 \\
Dehydroepiandrosterone sulfate & 162 & $152.39 \pm 73.24$ & 86 & $172.78 \pm 88.99$ & 0.152 \\
Desire domain & 165 & $2.85 \pm 0.9$ & 86 & $3.9 \pm 0.82$ & $<\mathbf{0 . 0 0 1}$ \\
Arousal domain & 165 & $2.95 \pm 0.89$ & 86 & $4.37 \pm 0.80$ & $<\mathbf{0 . 0 0 1}$ \\
Lubrication domain & 165 & $3.75 \pm 0.91$ & 86 & $4.88 \pm 0.72$ & $<\mathbf{0 . 0 0 1}$ \\
Orgasm domain & 165 & $3.52 \pm 0.98$ & 86 & $5.10 \pm 0.68$ & $<\mathbf{0 . 0 0 1}$ \\
Satisfaction domain & 165 & $3.83 \pm 1.26$ & 86 & $5.57 \pm 0.54$ & $<\mathbf{0 . 0 0 1}$ \\
Pain domain & 165 & $3.35 \pm 1.28$ & 86 & $4.65 \pm 1.11$ & $<\mathbf{0 . 0 0 1}$ \\
Total score & 165 & $20.27 \pm 3.80$ & 86 & $28.48 \pm 2.5$ & $<\mathbf{0 . 0 0 1}$ \\
\hline
\end{tabular}

${ }^{*}$ Mann-Whitney U test was done, $\mathrm{SD}=$ standard deviation

Table 5. Distribution of the participants' androgen levels, FSFI domain scores, and total FSFI scores according to the pregnancy situation

\begin{tabular}{lccccc}
\hline & \multicolumn{2}{c}{ Pregnancy absent } & \multicolumn{2}{c}{ Pregnancy present } & $\boldsymbol{p ~ v a l u e ~}^{*}$ \\
\cline { 2 - 5 } & $\mathbf{n}$ & Mean \pm SD & $\mathbf{n}$ & Mean \pm SD & $<0.001$ \\
Total testosterone & 114 & $0.46 \pm 0.20$ & 135 & $0.87 \pm 0.67$ & $<\mathbf{0 . 0 0 1}$ \\
1-4 delta androstenedione & 113 & $1.97 \pm 1.13$ & 134 & $3.37 \pm 2.52$ & $<\mathbf{0 . 0 0 1}$ \\
Dehydroepiandrosterone sulfate & 114 & $178.39 \pm 79.53$ & 134 & $143.36 \pm 76.06$ & $<\mathbf{0 . 0 0 1}$ \\
Desire domain & 114 & $3.27 \pm 1.03$ & 137 & $3.16 \pm 0.97$ & 0.30 \\
Arousal domain & 114 & $3.51 \pm 1.08$ & 137 & $3.37 \pm 1.11$ & 0.22 \\
Lubrication domain & 114 & $3.96 \pm 1.07$ & 137 & $4.28 \pm 0.92$ & 0.02 \\
Orgasm domain & 114 & $4.12 \pm 1.19$ & 137 & $4.01 \pm 1.14$ & 0.52 \\
Satisfaction domain & 114 & $4.52 \pm 1.32$ & 137 & $4.34 \pm 1.38$ & 0.28 \\
Pain domain & 114 & $3.83 \pm 1.41$ & 137 & $3.76 \pm 1.34$ & 0.55 \\
Total score & 114 & $23.25 \pm 5.38$ & 137 & $22.95 \pm 5.02$ & 0.60 \\
\hline
\end{tabular}

*Mann-Whitney U test was done, $\mathrm{SD}=$ standard deviation 


\begin{tabular}{|c|c|c|c|c|c|c|c|c|c|c|c|}
\hline \multicolumn{12}{|l|}{ Sexual dysfunction present } \\
\hline & & 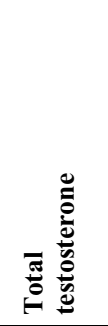 & 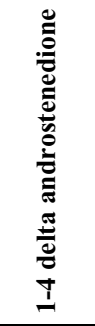 & 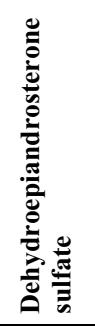 & 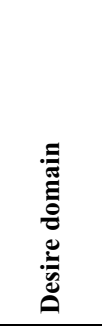 & 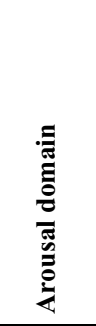 & 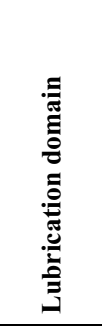 & 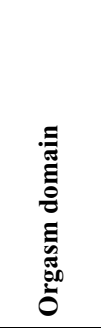 & 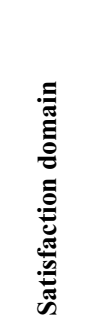 & 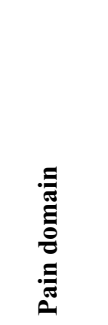 & 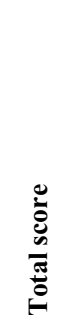 \\
\hline Total testosterone & rho & 1.000 & & & & & & & & & \\
\hline 1-4 delta androstenedione & rho & $0.536^{* *}$ & 1.000 & & & & & & & & \\
\hline Dehydroepiandrosterone sulfate & rho & 0.107 & $0.263^{* *}$ & 1.000 & & & & & & & \\
\hline Desire domain & rho & 0.031 & 0.032 & 0.083 & 1.000 & & & & & & \\
\hline Arousal domain & rho & $0.167^{*}$ & 0.043 & 0.092 & $0.513^{* *}$ & 1.000 & & & & & \\
\hline Lubrication domain & rho & $0.264^{* *}$ & $0.211^{* *}$ & 0.035 & $0.225^{* *}$ & $0.360^{* *}$ & 1.000 & & & & \\
\hline Orgasm domain & rho & 0.053 & $0.156^{*}$ & 0.073 & $0.363^{* *}$ & $0.439^{* *}$ & $0.387^{* *}$ & 1.000 & & & \\
\hline Satisfaction domain & rho & 0.125 & 0.053 & 0.006 & $0.370^{* *}$ & $0.456^{* *}$ & $0.284^{* *}$ & $0.477^{* *}$ & 1.000 & & \\
\hline Pain domain & rho & 0.108 & 0.065 & -0.045 & -0.093 & -0.069 & 0.091 & -0.036 & -0.083 & 1.000 & \\
\hline Total score & rho & $0.212^{* *}$ & $0.174^{*}$ & 0.104 & $0.614^{* *}$ & $0.701^{* *}$ & $0.610^{* *}$ & $0.656^{* *}$ & $0.678^{* *}$ & $0.260^{* *}$ & 1.000 \\
\hline
\end{tabular}

When the androgen levels and FSFI total and domain scores of the pregnant and nonpregnant women were compared, it was found that the pregnant women's total testosterone levels $(p<0.001)$, androstenedione levels $(p<0.001)$, and FSFI lubrication domain scores were significantly high $(p$ $=0.02$ ), while their DHEAS levels were significantly low $(p<0.001)$. There was not any significant difference according to the FSFI total scores between pregnant and nonpregnant women (Table 5).

When the correlation between the androgen levels and the FSFI domain and total scores in the women with sexual dysfunction were evaluated, there were significant correlations between the total testosterone level and the FSFI arousal domain $(\mathrm{r}=0.167, p<$ 0.05), FSFI lubrication domain $(\mathrm{r}=0.264, p<0.01)$, and FSFI total score $(\mathrm{r}=0.212, p<0.01)$. Additionally, there were significant correlations between the androstenedione level and the FSFI lubrication domain $(r=0.211, p<0.01)$, FSFI orgasm domain $(\mathrm{r}=0.156, p<0.05)$, and FSFI total score $(\mathrm{r}=$ $0.174, p<0.05)$ (Table 6).

The independent predictors of sexual dysfunction using the possible factors in the multivariate analysis were examined using a logistic regression analysis (Table 7). Evaluated input factors were age, bmi, gravidity, number of vaginal birth, number of caesarean section, educational attainment, working condition, income, total testosterone, dehydroepiandrosterone sulfate (DHEAS), and 1-4 delta androstenedione. It was observed that an increase in the DHEA level increased the sexual dysfunction by 0.996 -fold. The women with one pregnancy had 3.312-fold greater sexual dysfunction than the women without any pregnancies. Those women with more than eight years of education had 0.358 times more sexual dysfunction than those with eight years of education and less. This suggests that with an increasing educational level, sexual dysfunction decreases.

Table 7. Logistic regression analysis for sexual dysfunction

\begin{tabular}{lcc}
\hline Risk factors & $\boldsymbol{p}$ value & OR (95\% CI) \\
\hline Dehydroepiandrosterone sulfate & 0.026 & $0.996(0.992-0.999)$ \\
Gravida 0 & referent & \\
Gravida 1 & 0.039 & $3.312(1,061-10,339)$ \\
Gravida $\geq \mathbf{2}$ & 0.073 & $3.711(0.886-15.551)$ \\
Educational attaintment $(\leq \mathbf{8}$ years) & referent & \\
Educational attaintment $(>\mathbf{8}$ years) & 0.001 & $0.358(0.193-0.665)$ \\
\hline
\end{tabular}

$\mathrm{OR}=$ odds ratio, $\mathrm{CI}=$ Confidence Interval 


\section{DISCUSSION}

In the current study, which was performed with a sample of Turkish women, we found that the sexual dysfunction rate was $65.7 \%$, of which $58.8 \%$ were pregnant and $41.2 \%$ were not. In their meta-analysis, McCool et al. [22] evaluated 95 studies of premenopausal sexual dysfunction, excluding pregnant and lactating women, and they found an estimated FSD prevalence of $40.9 \%(95 \% \mathrm{CI}=37.1$ $44.7, \mathrm{I} 2=99.0 \%$ ). They reported the different FSD prevalence estimates in the different regions of the world as follows: $39.1 \%$ in Europe, $40.2 \%$ in Asia, $45.5 \%$ in Central and South America, $47.0 \%$ in the Middle East, and $61.7 \%$ in Africa [22]. Ninivaggio et al. [23] evaluated the sexual function of 623 nulliparous pregnant women using the FSFI in the first (T1), second (T2) and early third (T3) trimesters. They reported sexual dysfunction rates of $36.3 \%$ in $\mathrm{T} 1$, $36.8 \%$ in $\mathrm{T} 2$, and $57 \%$ in $\mathrm{T} 3$, and that the mean FSFI scores decreased as pregnancy progressed. In the previous studies conducted with reproductive aged nonpregnant Turkish women, Oksuz and Malhan [21] and Aslan et al. [5] reported the rates of sexual dysfunction as $48.3 \%$ and $43.4 \%$, respectively. In the study by Seven et al. [24], which was conducted in pregnant Turkish women, the rate of sexual dysfunction was $77.6 \%$. Ery1lmaz et al. [25] evaluated 238 Turkish pregnant women, and they reported that in $81.5 \%$ of them, their sexual lives were affected during pregnancy. In the studies by Erol et al. [26] and Çorbacioğlu et al. [27] conducted with Turkish pregnant women, the total FSFI scores and third trimester FSFI scores were significantly lower than the first and second trimester scores. The high sexual dysfunction rates of the Turkish reproductive aged women could be attributed to their social, cultural, religious, and educational attitudes. Inadequate education about sexual health, shame when talking about sexuality, acceptance when talking about sexuality as a sin, and shame in Eastern populations could be accepted as causes.

When evaluating women with sexual dysfunction present and absent, we did not find any differences according to the androgen levels. In a cross-sectional study by Davis et al. [28], the relationships between the androgens and sexual function were investigated in 1,423 non-healthcare-seeking women aged 18-75 years old. They did not find any relationships between the androstenedione, total testosterone, and free testosterone levels and the sexual function scores.

In the present study, we did not find any differences in terms of the total and domain scores, with the exception of the lubrication scores, between the pregnant and nonpregnant women. The lubrication scores in the pregnant women were higher because lubrication intensifies due to the increased genital vasocongestion during sexual excitement in pregnancy [29]. In the comparison of the serum androgen levels between the pregnant and nonpregnant women, we found higher total testosterone and androstenedione levels and lower DHEAS levels. The level of maternal testosterone increases [30] and the level of DHEAS decreases by about two times during pregnancy [31]. In addition, the serum level of the sex hormone binding globulin that binds a large fraction of testosterone increases and the percentage of free testosterone decreases during pregnancy. According to our results, although there were significant differences in the androgen levels between the pregnant and nonpregnant women, the FSFI total scores were not different.

In the current study, we found significant correlations between the androgen levels and the FSFI scores. There were significant correlations between the total testosterone level and the FSFI total, FSFI arousal domain, and FSFI lubrication domain scores. Additionally, there were significant correlations between the androstenedione level and the FSFI total, FSFI lubrication domain, and FSFI orgasm domain scores. Different from our results, Erol et al. [26] did not find any correlations between the androgen levels and the FSFI scores in their study of 589 pregnant women. Jacobsen et al. [32] studied the relationships between the androgen levels and sexual desire in 560 healthy women aged 19-65 years old, and they found significant correlations between the free testosterone, androstenedione, and FSFI desire domain in the total cohort of women. Garcia et al. [2] conducted a study of 101 women aged 18-55 years old, and there was no relationship between the free testosterone level and the FSFI scores. Of those 29 women with androgenic deficiencies, 14 had sexual dysfunction and 15 did not have sexual dysfunction [2]. These heterogeneous 
results could be explained by either the lack of sensitivity of the scale or the hypothesis that FSD is much more than just a hormonal problem. In addition to hormonal factors, cultural, social, traditional, psychosocial, developmental, religious, interpersonal, and medical factors are often relevant when measuring FSD [33].

We evaluated the independent predictors of sexual dysfunction using sociodemographic and hormonal variables, and we found that gravida 1 , more than 8 years of education, and DHEA were significant predictors. When compared to the women with no pregnancies, the women having one pregnancy had an increased risk of sexual dysfunction. Pregnancy has an effect on the sexual health via a decrease in sexual function throughout pregnancy, particularly during the third trimester $[26,34,35]$. In addition, the women having more than 8 years of education exhibited a decreased risk of sexual dysfunction when compared to the women with 8 years of education and less. Laumann and Paik [36] evaluated the prevalence and predictors of sexual dysfunction among 1,749 women aged 18-59 years old in the United States. They reported that sexual dysfunction was associated with various demographic characteristics, including age and education. Those women who were college graduates had lesser degrees of low sexual desire, problems achieving orgasm, sexual pain, and sexual anxiety when compared to the women who did not graduate from high school [36]. Eryılmaz et al.[25], in their study of 238 Turkish pregnant women, reported significant relationships between the changes in sexual life during pregnancy and the marriage duration, educational level, parity, and gravidity. According to our results, an increase in the level of DHEA was related to a decrease in the level of sexual dysfunction. In an Australian study evaluating the relationship between the androgen levels and selfreported sexual function with 1,423 women from 18-75 years old, there was no association between the testosterone and the self-reported sexual function. However, in those women between 18 and 44 years old with decreased sexual desire, the sexual arousal or sexual responsiveness was associated with a DHEAS value below the 10th percentile for age [28].

\section{Limitations}

The limitations of this study include the fact that it was a cross-sectional study and not prospective. The comparisons were done among different women, not with the same women before and after pregnancy. In addition, we did not measure the level of free testosterone because of our limited assays. Finally, we did not ask about any history of sexual dysfunction before pregnancy or include questions about the partners' roles or conditions related to sexual dysfunction.

\section{CONCLUSION}

Although we evaluated the sexual dysfunction among a small group of pregnant and nonpregnant Turkish women, we found a high prevalence, as reported in the literature. Although the serum androgen levels change during pregnancy, there were no significant differences according to the FSFI total scores between the pregnant and nonpregnant women. In addition, there were no significant differences in the androgen levels of the women with and without sexual dysfunction. There were significant correlations between the total testosterone level and the FSFI arousal domain, FSFI lubrication domain, and FSFI total scores. Additionally, there were significant correlations between the androstenedione level and the FSFI lubrication domain, FSFI orgasm domain, and FSFI total scores. When compared to the women with no pregnancies, the women with one pregnancy had an increased risk of sexual dysfunction. Based on our results, any increase in the DHEAS level and educational level of a woman was observed to decrease the development of sexual dysfunction.

Overall, sexual dysfunction is a multifactorial entity. Future prospective studies evaluating the reasons for sexual dysfunction with larger populations from different cultures and countries could help professionals understand the multifactorial dimensions of this public health problem. In addition, healthcare professionals should give more time for better counselling about sexuality during pregnancy at prenatal visits.

\section{Authors' Contributions}

BSA: Study design, data drafting, statistical analysis, interpretation of data writing; IK: Study design, interpretation of data, writing 


\section{Conflict of interest}

The authors disclosed no conflict of interest during the preparation or publication of this manuscript.

\section{Financing \\ The authors disclosed that they did not receive any grant during conduction or writing of this study.}

\section{REFERENCES}

[1] Sexual dysfunctions. In: Diagnostic and Statistical Manual of Mental Disorders. American. Psychiatric Association. 5th ed., 2013.

[2] Garcia S, Moreno S, Aponte H. Prevalence of sexual dysfunction in female outpatients and personnel at a Colombian hospital: correlation with hormonal profile. J Sex Med 2008;5:1208-13.

[3] Laumann EO, Nicolosi A, Glasser DB, Paik A, GingellC, Moreira, et al; Gssab Investigators' Group. Sexual problems among women and men aged 40-80 y: prevalence and correlates identified in the Global Study of Sexual Attitudes and Behaviors. Int J Impot Res 2005; 17:39-57.

[4] Cayan S, Akbay E, Bozlu M, Canpolat B, Acar D, Ulusoy E. The prevalence of female sexual dysfunction and potential risk factors that may impair sexual function in Turkish women. Urol Int 2004;72:52-7.

[5] Aslan E, Beji NK, Gungor I, Kadioglu A, Dikencik BK. Prevalence and risk factors for low sexual function in women: a study of 1,009 women in an outpatient clinic of a university hospital in Istanbul. J Sex Med 2008;5:2044-52.

[6] Oruç S, Esen A, Laçin S, Adigüzel H, Uyar Y, Koyuncu F. Sexual behaviour during pregnancy. Aust NZ J Obstet Gynaecol 1999;39:48-50.

[7] Lee JT. The meaning of sexual satisfaction in pregnant Taiwanese women. J Midwifery Womens Heal 2002;47:278-86. [8] von Sydow K. Sexuality during pregnancy and after childbirth: a meta content analysis of 59 studies. J Psychosom Res 1999;47:27-49.

[9] Orji EO, Ogunlola IO, Fasubaa OB. Sexuality among pregnant women in South West Nigeria. J Obstet Gynaecol 2002;22:166-8.

[10] Sayle AE, Savitz DA, Thorp JM Jr, Hertz-Picciotto I, Wilcox AJ. Sexual activity during late pregnancy and risk of preterm delivery. Obstet Gynecol 2001;97:283-9.

[11] Read JS Klebanoff MA. Sexual intercourse during pregnancy and preterm delivery:effects of vaginal microorganisms. The Vaginal Infections and Prematurity Study Group. Am J Obstet Gynecol 1993;168:514-9.

[12] Heinig L, Engfer A. Schwangerschaft und Partnerschaft. Rep Psychol 1988;13:56-9.

[13] Elraiyah T, Sonbol MB, Wang Z, Khairalseed T, Asi N, Undavalli $\mathrm{C}$, et al. The benefits and harms of systemic dehydroepiandrosterone (DHEA) in postmenopausal women with normal adrenal function: a systematic review and meta- analysis. J Clin Endocrinol Metab 2014;99:3536-42.

[14] Dennerstein L, Dudley EC, Hopper JL, Burger H. Sexuality, hormones and the menopausal transition. Maturitas 1997;26:8393.

[15] Baulieu EE, Thomas G, Legrain S, Lahlou N, Roger M, Debuire B, et al. Dehydroepiandrosterone (DHEA), DHEA sulfate, and aging: contribution of the DHEAge Study to a sociobiomedical issue. Proc Natl Acad Sci U S A 2000;97:427984.

[16] Panjari M, Bell RJ, Jane F, Wolfe R, Adams J, Morrow C, et al. A randomized trial of oral DHEA treatment for sexual function, well-being, and menopausal symptoms in postmenopausal women with low libido. J Sex Med 2009;6:257990.

[17] Hackbert L, Heiman JR. Acute dehydroepiandrosterone (DHEA) effects on sexual arousal in postmenopausal women. $\mathrm{J}$ Womens Health Gend Based Med 2002;11:155-162.

[18] Schmidt PJ, Daly RC, Bloch M, Smith MJ, Danaceau MA, St Clair LS, et al. Dehydroepiandrosterone monotherapy in midlife-onset major and minor depression. Arch Gen Psychiatry 2005;62:154-62.

[19] Rosen R, Brown C, Heiman J, Leiblum S, Meston C, Shabsigh R, et al. The Female Sexual Function Index (FSFI): a multidimensional self-report instrument for the assesment of female sexual function. J Sex Marital Ther 2000;26:191-208.

[20] Öksüz E, Malhan S. [Reliability and validity of the female sexual function index in Turkish population]. Sendrom 2005;17:54-9. [Article in Turkish]

[21] Oksuz E, Malhan S. Prevalence and risk factors for female sexual dysfunction in Turkish women. J Urol 2006;175:654-8.

[22] McCool ME, Zuelke A, Theurich MA, Knuettel H, Ricci C, Apfelbacher C. Prevalence of female sexual dysfunction among premenopausal women: a systematic review and meta-analysis of observational studies. Sex Med Rev 2016;4:197-212.

[23] Ninivaggio C, Rogers RG, Leeman L, Migliaccio L, Teaf D, Qualls C. Sexual function changes during pregnancy. Int Urogynecol J 2017;28:923-9.

[24]. Seven M, Akyüz A, Güngör S. Predictors of sexual function during pregnancy. J Obstet Gynaecol 2015;35:691-5.

[25] Eryılmaz G, Ege E, Zincir H. Factors affecting sexual life during pregnancy in eastern Turkey. Gynecl Obs Invest 2004;57:103-8.

[26] Erol B, Sanli O, Korkmaz D, Seyhan A, Akman T, Kadioglu A. A cross-sectional study of female sexual function and dysfunction during pregnancy. J Sex Med 2007;4:1381-7.

[27] Corbacıoglu Esmer A, Akca A, Akbayir O, Goksedef BP, Bakir VL. Female sexual function and associated factors during pregnancy. J Obstet Gynaecol Res 2013;39:1165-72.

[28] Davis SR, Davison SL Donath S, Bell RJ. Circulating androgen levels and self-reported sexual function in women. JAMA 2005;294:91-6.

[29] von Sydow K. Sexuality during pregnancy and after childbirth: a metacontent analysis of 59 studies. J Psychosom Res 1999;47:27-49.

[30] Morel Y, Roucher F, Plotton I, Goursaud C, Tardy D. Evolution of steroids during pregnancy: maternal, placental and fetal synthesis. Ann Endocrinol (Paris) 2016;77:82-9. 
[31] Hill M, Pašková A, Kančeva R, Velíková M, Kubátová J, [34] Pauleta J, Pereira NM GL. Sexuality during pregnancy. J Kancheva L, et al. Steroid profiling in pregnancy: a focus on the Sex Med. 2010;7:136-42.

human fetus. J Steroid Biochem Mol Biol 2014;139:201-22.

[32] Wåhlin-Jacobsen S, Pedersen AT, Kristensen E, Læssøe NC, Lundqvist $\mathrm{M}$, Cohen $\mathrm{AS}$, et al. Is there a correlation between androgens and sexual desire in women? J Sex Med 2015;12:358-

73.

[35] Fok W, Chan LY, Yuen PM. Sexual behavior and activity in Chinese pregnant women. Acta Obstet Gynecol Scand 2005;84:934-8.

[36] Laumann EO, Paik A Rosen RC. Sexual dysfunction in the [33] Fourcroy JL. Customs, culture, and tradition - what role do United States: prevalence and predictors. JAMA 1999;281:537they play in a woman's sexuality? J Sex Med 2006;3:954-9. 